\title{
Effect of a multi-layer infection control barrier on the micro-hardness of a composite resin
}

\author{
In-Nam HWANG ${ }^{1}$, Sung-Ok HONG ${ }^{2}$, Bin-Na LEE ${ }^{3}$, Yun-Chan HWANG ${ }^{4}$, Won-Mann OH$^{1}$, Hoon-Sang CHANG ${ }^{5}$
}

1- DDS, MS, PhD, Professor, Department of Conservative Dentistry and Dental Science Research Institute, School of Dentistry, Chonnam National University,
Gwangju, Korea.
2- DDS, MS, Graduate Student, Department of Conservative Dentistry, School of Dentistry, Kyunghee University, Seoul, Korea.
3- DDS, MS, Graduate Student, Department of Conservative Dentistry, School of Dentistry, Chonnam National University, Gwangju, Korea.
4- DDS, MS, PhD, Associate Professor, Department of Conservative Dentistry, Dental Science Research Institute, School of Dentistry, Chonnam National
University, Gwangju, Korea.
5- DDS, MS, PhD, Assistant Professor, Department of Conservative Dentistry and Dental Science Research Institute, School of Dentistry, Chonnam National
University, Gwangju, Korea.

Corresponding address: Hoon-Sang Chang - Department of Conservative Dentistry - School of Dentistry - Chonnam National University - Yongbong-dong, Buk-gu - Gwangju - Korea - Phone +82-62-530-5860 - Fax. +82-62-530-5829 - e-mail: conden@jnu.ac.kr

Received: February 27, 2012 - Modification: August 16, 2012 - Accepted: September 13, 2012

\section{ABSTRACT}

\begin{abstract}
$\mathrm{O}$ bjective: The aim of this study was to evaluate the effect of multiple layers of an infection control barrier on the micro-hardness of a composite resin. Material and Methods: One, two, four, and eight layers of an infection control barrier were used to cover the light guides of a high-power light emitting diode (LED) light curing unit (LCU) and a low-power halogen LCU. The composite specimens were photopolymerized with the LCUs and the barriers, and the micro-hardness of the upper and lower surfaces was measured $(n=10)$. The hardness ratio was calculated by dividing the bottom surface hardness of the experimental groups by the irradiated surface hardness of the control groups. The data was analyzed by two-way ANOVA and Tukey's HSD test. Results: The micro-hardness of the composite specimens photopolymerized with the LED LCU decreased significantly in the four- and eight-layer groups of the upper surface and in the two-, four-, and eight-layer groups of the lower surface. The hardness ratio of the composite specimens was $<80 \%$ in the eight-layer group. The micro-hardness of the composite specimens photopolymerized with the halogen LCU decreased significantly in the eight-layer group of the upper surface and in the two-, four-, and eight-layer groups of the lower surface. However, the hardness ratios of all the composite specimens photopolymerized with barriers were $<80 \%$. Conclusions: The two-layer infection control barrier could be used on high-power LCUs without decreasing the surface hardness of the composite resin. However, when using an infection control barrier on the low-power LCUs, attention should be paid so as not to sacrifice the polymerization efficiency.
\end{abstract}

Key words: Composite resins. Dental curing lights. Dental infection control. Hardness tests.

\section{INTRODUCTION}

Dental offices must maintain a high level of infection control to protect both the patients and personnel. During the light curing of direct composite resin restorations, contamination of the light guides and light curing unit (LCU) handles are common after clinical use ${ }^{7}$. In particular, the light guide is in direct contact with the oral mucous membrane, and thus there is always a possibility of infection. According to the Centers for Disease
Control and Prevention (CDC) Guidelines for Infection Control in Dental Health-Care Settings ${ }^{17}$, patient-care items (dental instruments, devices, and equipment) are categorized as critical, semicritical, or non-critical, depending on the potential risk for infection associated with their intended use. The light guide of a dental LCU falls into the category of semi-critical instruments because it is in direct contact with the mucous membranes or non-intact skin and carries the risk of infection transmission. Therefore, light guides should be 
sterilized with heat or, at a minimum, processed with high-level disinfection. Unfortunately, light guide tips build up boiler scale from vaporized water when autoclaved and require frequent polishing to retain optimal light intensity. Chemical sterilization requiring up to 10 hours of immersion is not always practical, and not all offices have access to vapor sterilization ${ }^{15,20,25}$. Therefore, disposable infection control barriers are frequently used, as they provide a cost-effective way of avoiding contamination of the light guide ${ }^{8}$. Disposable barriers are convenient, non-invasive, and prevent contact between the oral tissues and the light guide. These types of barriers also eliminate the risk of damaging the light guide during autoclaving or disinfection ${ }^{10,19,22,27}$. Among various infection control barriers, the plastic wrap has the least effect on the LCU power density ${ }^{19,27}$. However, a thin single-layer infection control barrier tends to tear easily while manipulating the LCU, or by the sharp edges of the prepared tooth during the light curing procedure while trying to keep the light guide tip as close to the prepared cavity as possible. Therefore, using a multi-layer infection control barrier could reduce the risk of cross infection. However, a multi-layer infection control barrier was reported to reduce the light output of the $\mathrm{LCUs}^{9}$ and consequently could affect the polymerization of the composite resin.

The aim of this paper was to evaluate the effect of a multi-layer infection control barrier on the micro-hardness of a composite resin light cured with a high-power density light emitting diode (LED) LCU and a low-power density halogen LCU. The null hypothesis tested was that neither the layers of infection control barriers nor the LCUs would have a significant effect on the micro-hardness of the composite resin.

\section{MATERIAL AND METHODS}

The light guides of a high-power density LED LCU (Elipar FreeLight 2, 3M ESPE, St Paul, MN, USA, FL2, Figure 1) and a low-power density halogen LCU (Optilux 360, Demetron, Danbury, CT, USA, O360) were covered with one, two, four, and eight layers of a disposable wrap barrier (Cleanwrap, Gimhae, Korea). The barrier was cut to an adequate size and was used to cover the light guide without air entrapment but with an overlap on the light guide tip. To evaluate the micro-hardness of the composite resin specimens, an A2 shade flowable resin (Denfil Flow, Vericom, Anyang, Korea) was filled into a stainless steel mold of $5 \mathrm{~mm}$ diameter and $2 \mathrm{~mm}$ depth. The diameter of the specimen was smaller than the diameter of the two LCU light guides so as to light cure the entire area of the specimen in 20 seconds. A glass slab covered with polyester film was pressed against the mold in order to control the thickness of the specimen. After removing the glass slab, the composite resin was light cured for 20 seconds using the LCUs covered with a disposable barrier. The specimens were removed from the mold and the Vickers microhardness testing was performed immediately with a micro-hardness tester (MHT-10, Anton Paar, Graz, Austria) with a $100 \mathrm{~g}$ load for 10 seconds dwell time, at 3 points in the center of the upper and lower surfaces of the composite resin forming a small triangle, and the mean Vickers hardness number (VHN) was determined. The VHN of the irradiated surface of the composite resin specimens light cured with LCUs that was not covered with a barrier was recorded as the control. The hardness ratio was derived by dividing the VHN of the bottom surface of the composite resin specimens of the experimental groups by the VHN of the irradiated surface of the control groups with the corresponding LCUs. Ten composite specimens were used to measure the micro-hardness in each test group. The VHN and the hardness ratio of the composite resin specimens were analyzed with two-way analysis of variance (ANOVA) (SPSS 12.0K, SPSS Inc., Chicago, IL, USA) to examine 2 factors, layers of infection control barrier and LCUs and their interaction. One-way ANOVA and Tukey's HSD tests were performed for the comparison of 4 different numbers of layers and the Student's t-test was performed for the comparison of 2 types of LCUs. The null hypotheses of no difference were rejected if the $p$-values were less than .05 .

\section{RESULTS}

The VHNs of the upper surface of the composite resin specimens light cured with LCUs covered with barriers are shown in Table 1. The two-way ANOVA showed a significant effect for both the main factors (layers, $p<0.001$; LCUs, $p<0.001$ )

\begin{tabular}{|c|c|c|c|}
\hline Group & $\begin{array}{l}\text { Light curing unit } \\
\text { (Manufacturer) }\end{array}$ & $\begin{array}{l}\text { Power density (standard } \\
\text { deviation) in } \mathrm{mW} / \mathrm{cm}^{2}\end{array}$ & Light source \\
\hline FL2 & Elipar FreeLight 2 (3M ESPE) & $1005(4)$ & LED \\
\hline 0360 & Optilux 360 (Demetron) & $519(5)$ & QTH \\
\hline
\end{tabular}

The power density was measured with a hand-held dental radiometer (Cure Rite, Kerr, Milford, MA, USA, $n=10$ )

Figure 1- Description of the light curing units used in this study 
Table 1- Means (standard deviations) of Vickers hardness number (VHN) of the upper surface of composite resin specimens light cured with light curing units covered with layers of an infection control barrier

\begin{tabular}{cccccc}
\hline LCU & Control & 1 Layer & 2 Layers & 4 Layers & 8 Layers \\
\hline FL2 & $28.1(1.2)^{\mathrm{Aa}}$ & $28.0(1.2)^{\mathrm{Aa}}$ & $27.6(0.9)^{\mathrm{Aa}}$ & $26.1(0.7)^{\mathrm{Ba}}$ & $24.6(1.0)^{\mathrm{Ca}}$ \\
O360 & $20.2(1.1)^{\mathrm{Ab}}$ & $19.7(1.3)^{\mathrm{ABb}}$ & $19.2(0.9)^{\mathrm{ABb}}$ & $19.2(1.0)^{\mathrm{ABb}}$ & $18.5(0.9)^{\mathrm{Bb}}$ \\
\hline
\end{tabular}

Values having the same capital letters in the rows and the same small letters in the columns are not statistically significant ( $p>0.05)$. LCU= light curing unit; FL2= Elipar FreeLight 2; O360= Optilux 360

Table 2- Means (standard deviations) of Vickers hardness number (VHN) of the lower surface of composite resin specimens light cured with light curing units covered with layers of an infection control barrier

\begin{tabular}{cccccc}
\hline LCU & Control & 1 Layer & 2 Layers & 4 Layers & 8 Layers \\
\hline FL2 & $25.2(0.6)^{\mathrm{Aa}}$ & $24.7(0.9)^{\mathrm{ABa}}$ & $23.8(1.1)^{\mathrm{BCa}}$ & $23.4(0.9)^{\mathrm{Ca}}$ & $21.4(1.2)^{\mathrm{Ca}}$ \\
$\mathrm{O} 360$ & $16.1(0.9)^{\mathrm{Ab}}$ & $15.3(0.7)^{\mathrm{ABb}}$ & $14.4(0.9)^{\mathrm{BCb}}$ & $13.5(0.9)^{\mathrm{CDb}}$ & $13.2(0.7)^{\mathrm{Db}}$ \\
\hline
\end{tabular}

Values having the same capital letters in the rows and the same small letters in the columns are not statistically significant ( $p>0.05)$. LCU= light curing unit; FL2= Elipar FreeLight 2; O360= Optilux 360

Table 3- Hardness ratios (standard deviations) of composite resin specimens light cured with light curing units covered with layers of an infection control barrier

\begin{tabular}{cccccc}
\hline LCU & Control & 1 Layer & 2 Layers & 4 Layers & 8 Layers \\
\hline FL2 & $89.8(2.0)^{\mathrm{Aa}}$ & $88.2(5.1)^{\mathrm{Aba}}$ & $84.5(6.0)^{\mathrm{Aba}}$ & $83.4(5.3)^{\mathrm{Ba}}$ & $76.4(5.7)^{\mathrm{Ca}}$ \\
O360 & $80.0(5.2)^{\mathrm{Ab}}$ & $76.1(4.4)^{\mathrm{Abb}}$ & $72.0(5.2)^{\mathrm{BCb}}$ & $66.9(4.7)^{\mathrm{Cb}}$ & $65.6(6.2)^{\mathrm{Cb}}$ \\
\hline
\end{tabular}

Values having the same capital letters in the rows and the same small letters in the columns are not statistically significant ( $p>0.05$ ). LCU= light curing unit; FL2= Elipar FreeLight 2; O360= Optilux 360

and their interaction $(p<0.01)$. The VHNs were significantly higher in all groups light cured with the FL2 LCU than in those light cured with the 0360 LCU $(p<0.05)$. In the groups light cured with the FL2 LCU, significant differences were observed between the control group and the four- and eightlayer groups $(p<0.05)$. In the groups light cured with the $0360 \mathrm{LCU}$, significant differences were observed between the control group and the eightlayer group $(p<0.05)$. The control group light cured with the FL2 LCU showed a significantly higher VHN than that in the control group light cured with the O360 LCU $(p<0.05)$.

The VHNs of the lower surface of the composite resin specimens light cured with the LCUs covered with barriers are shown in Table 2. The two-way ANOVA showed a significant effect for both the main factors (layers, $p<0.001$; LCUs, $p<0.001$ ) and their interaction $(p<0.05)$. Similar to the results of the upper surface hardness, the VHNs were significantly higher in all groups light cured with the FL2 LCU than in those light cured with the 0360 LCU $(p<0.05)$. Significant differences were observed between the control groups and the two-, four-, and eight- layer groups light cured with both LCUs $(p<0.05)$.

The hardness ratios of the lower surface hardness of the composite resin specimens to the upper surface hardness of the control specimens of the corresponding LCUs are shown in Table 3. The two-way ANOVA showed a significant effect for both the main factors (layers, $p<0.001$; LCUs, $p<0.001$ ) and an insignificant effect for their interaction $(p>0.05)$. The hardness ratios of the composite resin specimens light cured with the FL2 LCU were $89.8 \%$ for the control group and $88.2 \%, 84.5 \%$, and $83.4 \%$ for the one-layer, two-layer, and four-layer groups, respectively. The hardness ratio was $76.4 \%$ for the eight-layer group, showing a hardness ratio of $<80 \%$. The differences of the hardness ratio between the control and the four-layer, and eight-layer groups were statistically significant $(p<0.05)$. The hardness ratios of the composite resin specimens light cured with the 0360 LCU were between $65.6 \%$ and $80.0 \%$. Significant differences were observed between the control group and the two-layer, four-layer, and eight-layer groups $(p<0.05)$. However, only the control group showed a hardness ratio of $80 \%$.

\section{DISCUSSION}

The Vickers micro-hardness test was performed as an indirect method to evaluate the degree of 
conversion of the composite resin $1,3,4,6,11,12,14,16,23,28$. In this study, the micro-hardness was tested immediately after the light curing procedure because the occlusal adjustment, finishing and polishing of the composite resin restorations are usually performed just after light curing the composite resin in clinical situations. Stress created by these procedures can have a detrimental effect on the tooth-restoration interface, such as the premature breakdown of the restoration at the margin $2,22,24$.

The micro-hardness of the composite resin specimens was significantly different according to the LCUs and the thicknesses of the infection control barrier therefore, the null hypothesis was rejected. The micro-hardness of the upper surface of the composite resin specimens was significantly lower in the groups light cured with the FL2 LCU covered with four and eight layers of an infection control barrier as compared to the control group. The groups light cured with the FL2 LCU covered with one and two layers of an infection control barrier had VHNs similar to that of the control group. Therefore, an infection control barrier comprised of more than four layers affected the hardness of the upper surface of the composite resin specimens. A significant difference was noted in the group light cured with the 0360 LCU covered with eight layers as compared to the control group. The other groups showed no significant differences. Therefore, an LED LCU covered with a multi-layer barrier affected the polymerization of the upper surface of the specimens more than that with the halogen LCU. In addition, the surface hardness of all groups including the control group light cured with the 0360 LCU was significantly lower than that light cured with the FL2 LCU. This result suggests that 20 seconds of light curing with the 0360 LCU may be insufficient for adequate polymerization of the composite resin.

Unlike the upper surface hardness, significant differences were seen in the micro-hardness of the lower surface of the composite resin specimens light cured with both LCUs covered with two, four, and eight layers as compared to the control group. Therefore, the hardness of the lower surface was suspected to have been affected more by the use of a multi-layer barrier than that of the upper surface. Similar to the upper surface, the VHNs of the lower surface were significantly lower when light cured with the 0360 LCU as compared with the FL2 LCU.

The Vickers micro-hardness of the specimens light cured with LCUs covered with one layer of an infection control barrier agrees with a previous study. They found no significant difference in the hardness of composite resins between those that were light cured with halogen and LED LCUs that were not covered with a sheath and those that were light cured with halogen and LED LCUs that were covered with a single sheath ${ }^{20}$. The decrease of surface hardness of the composite resin specimens light cured with LCUs and infection control barriers in multiple layers could be explained by the decrease of the power density of LCUs due to the infection control barriers. In our previous study, the power density of the FL2 LCU with one-, two, four-, and eight-layer infection control barriers decreased by $3 \%, 4 \%, 6 \%$, and $8 \%$, respectively. The power density of the 0360 with the infection control barriers decreased by $4 \%, 5 \%, 8 \%$ and $12 \%$, respectively ${ }^{9}$.

The degree of conversion of the composite resin specimen is usually assessed by the hardness ratio, the ratio between the upper surface hardness value of the control group and the lower surface hardness value of the experimental group light cured with corresponding LCUs. The hardness ratio should not be less than $80 \%$ for composite resins that are adequately cured $5,13,18,21,26$. The hardness ratio of the composite resin specimens light cured with the FL2 LCU was significantly lower in the four- and eight-layer groups compared to the control group. Moreover, the hardness ratio of the eight-layer group was $<80 \%$, indicating insufficient photopolymerization of the composite resin specimen. The hardness ratio of the composite resin specimens light cured with the 0360 LCU was significantly lower in the two-, four-, and eight-layer groups. However, only the control group showed a hardness ratio of $80 \%$, and the experimental groups showed hardness ratios of less than $80 \%$, indicating insufficient photopolymerization of the tested composite resin specimens.

Interactions were observed in the statistical analysis of the surface hardness values. This might be explained by the different curing light diffusion of the two LCUs. In our previous study, the curing light diffusion of the FL2 LCU was measured as 75 degrees, whereas that of the 0360 LCU was measured as 48 degrees $^{9}$. We suspect that the more focused curing light of the halogen LCU was less affected by a multi-layer barrier compared with the less focused curing light of the LED LCU and this resulted in the difference in the hardness of the upper surface of the composite resin specimens and caused the interaction between the layers and LCUs.

Based on the results of this in vitro study, two layers rather than one layer of an infection control barrier should be used in order to decrease the possibility of cross infection during the light curing procedure with high-power density LCUs.

\section{CONCLUSIONS}

Within the limitations of this in vitro study, onelayer and two-layer of an infection control barrier 
did not show any significant differences in the hardness ratio of the composite resin specimens cured with high-power density LCUs. However, when low-power density LCUs covered with infection control barriers are used, attention should be paid so as not to sacrifice the polymerization efficiency of the composite resin.

\section{ACKNOWLEDGEMENTS}

This study was financially supported by the Chonnam National University, 2011.

\section{REFERENCES}

1- Anfe TE, Caneppele TM, Agra CM, Vieira GF. Micro-hardness assessment of different commercial brands of resin composites with different degrees of translucence. Braz Oral Res. 2008;22:358-63. 2- Arrais CAG, Giannini M, Rueggeberg FA. Kinetic analysis of monomer conversion in auto- and dual-polymerizing modes of commercial resin luting cements. J Prosthet Dent. 2009;101:12836.

3- Asmussen E. Factors affecting the quantity of remaining double bonds in restorative resin polymers. Scand J Dent Res. 1982;90:490-6.

4- Asmussen E. Restorative resins: hardness and strength vs. quantity of remaining double bonds. Scand J Dent Res. 1982;90:484-9.

5- Briso AL, Fedel TM, Pereira SM, Mauro SJ, Sundfeld RH, Sundefeld ML. Influence of light curing source on the microhardness of composite resins of different shades. J Appl Oral Sci. 2006;14:10-5.

6- Bueno AL, Arrais CA, Jorge AC, Reis AF, Amaral CM. Lightactivation through indirect ceramic restorations: does the overexposure compensate for the attenuation in light intensity during resin cement polymerization? J Appl Oral Sci. 2011;19:227.

7- Caughman GB, Caughman WF, Napier N, Schuster GS. Disinfection of visible-light-curing devices. Oper Dent. 1989;14:27.

8- Chang HS. Infection control of light curing units. J Korean Acad Conserv Dent. 2010;35:235-7.

9- Chang HS, Lee SR, Hong SO, Ryu HW, Song CK, Min KS. Effect of infection control barrier thickness on light curing units. J Korean Acad Conserv Dent. 2010;35:368-73.

10- Chong SL, Lam YK, Lee FKF, Ramalingam L, Yeo ACP, Lim CC. Effect of various infection-control methods for light-cure units on the cure of composite resins. Oper Dent. 1998;23:150-4.

11- Della Bona A, Rosa V, Cecchetti D. Influence of shade and irradiation time on the hardness of composite resins. Braz Dent J. 2007;18:231-4.

12- Faria AC, Benassi UM, Rodrigues RC, Ribeiro RF, Mattos MG. Analysis of the relationship between the surface hardness and wear resistance of indirect composites used as veneer materials. Braz Dent J. 2007;18:60-4.
13- Furukawa K, Inai N, Tagami J. The effects of luting resin bond to dentin on the strength of dentin supported by indirect resin composite. Dent Mater. 2002;18:136-42.

14- Hass V, Folkuenig MS, Reis A, Loguercio AD. Influence of adhesive properties on resin-dentin bond strength of one-step self-etching adhesives. J Adhes Dent. 2011;13:417-24.

15- Kakaboura A, Tzoutzas J, Pitsinigos D, Vougiouklakis G. The effect of sterilization methods on the light transmission characteristics and structure of light-curing tips. J Oral Rehabil. 2004;31:918-23.

16- Koch A, Kroeger $M$, Hartung M, Manetsberger I, Hiller KA, Schmalz $G$, et al. Influence of ceramic translucency on curing efficiency of different light-curing units. J Adhes Dent. 2007;9:44962.

17- Kohn WG, Collins AS, Cleveland JL, Harte JA, Eklund KJ, Malvitz DM. Guidelines for infection control in dental health-care settings - 2003. MMWR Recomm Rep. 2003;52:1-61.

18- Lucey S, Lynch CD, Ray NJ, Burke FM, Hannigan A. Effect of pre-heating on the viscosity and micro-hardness of a resin composite. J Oral Rehabil. 2010;37:278-82.

19- McAndrew R, Lynch CD, Pavli M, Bannon A, Milward P. The effect of disposable infection control barriers and physical damage on the power output of light curing units and light curing tips. $\mathrm{Br}$ Dent J. 2011;210:E12.

20- Nelson SK, Caughman WF, Rueggeberg FA, Lockwood PE. Effect of glutaraldehyde cold sterilants on light transmission of curing tips. Quintessence Int. 1997;28:725-30.

21- Pilo R, Cardash HS. Post-irradiation polymerization of different anterior and posterior visible light-activated resin composites. Dent Mater. 1992;8:299-304.

22- Pollington S, Kahakachchi N, van Noort R. The influence of plastic light cure sheaths on the hardness of composite resin. Oper Dent. 2009;34:741-5.

23- Poskus LT, Latempa AM, Chagas MA, Silva EM, Leal MP, Guimarães JG. Influence of post-cure treatments on hardness and marginal adaptation of composite resin inlay restorations: an in vitro study. J Appl Oral Sci. 2009;17:17-22.

24- Ray NJ, Lynch CD, Burke FM, Hannigan A. Early surface microhardness of a composite resin exposed to a pulse-delayed curing exposure: a comparison of a tungsten halogen and a plasma arc lamp, in vitro. Eur J Prosthodont Restor Dent. 2005;13:177-81. 25- Rueggeberg FA, Caughman WF, Comer RW. The effect of autoclaving on energy transmission through light-curing tips. J Am Dent Assoc. 1996;127:1183-7.

26- Santos MJ, Passos SP, Encarnacao MO, Santos GC Jr, Bottino MA. Hardening of a dual-cure resin cement using QTH and LED curing units. J Appl Oral Sci. 2010;18:110-5.

27- Scott BA, Felix CA, Price RB. Effect of disposable infection control barriers on light output from dental curing lights. J Can Dent Assoc. 2004;70:105-10.

28- Thomé T, Steagall W Jr, Tachibana A, Braga SR, Turbino $M L$. Influence of the distance of the curing light source and composite shade on hardness of two composites. J Appl Oral Sci. 2007; 15:486-91. 